\title{
Magnitude of chronic energy deficiency and its associated factors among women of reproductive age in the Kunama population, Tigray, Ethiopia, in 2014
}

\author{
Saba Abraham ${ }^{1 *}$, Gebremeskel Miruts ${ }^{2}$ and Ashenafi Shumye ${ }^{2}$
}

\begin{abstract}
Background: Women in the reproductive age group are most vulnerable to malnutrition. Maternal and child undernutrition is the underlying cause of 3.5 million deaths each year and $11 \%$ of the total global disease burden. Among women in sub-Saharan Africa, 10-20\% are classified as excessively thin. The 2011 Ethiopian Demographic and Health Survey (EDHS) has reported that $27 \%$ of Ethiopian women and $40 \%$ of Tigray women of reproductive age are too thin. There is no previous study done on the nutritional status and associated factors of women of reproductive age among Kunama women, the minor group. The aim of the study is to assess the magnitude of chronic energy deficiency and its associated factors among women of reproductive age in the Kunama population in Northwest Tigray, Ethiopia, in 2014.
\end{abstract}

Methods: A community-based cross-sectional study was conducted in the Tahtay Adiyabo woreda, Northwest Tigray, Kunama population on 284 women of reproductive age who were selected using simple random sampling technique. Data was collected using structured face-to-face interview and anthropometric assessment from January 27 to March 7, 2014. Data were entered and analyzed using SPSS version 20. Logistic regression was done to identify factors that are associated with undernutrition.

Results: The prevalence of undernutrition/chronic energy deficiency (body mass index $<18.5 \mathrm{~kg} / \mathrm{m}^{2}$ ) was $47.9 \%$ (95\% Cl 42.11-53.7\%). Severe (BMl $\left.<16 \mathrm{~kg} / \mathrm{m}^{2}\right)$, moderate (BMl $<17$ to $\geq 16 \mathrm{~kg} / \mathrm{m}^{2}$ ), and mild undernutrition (BMI $<18.5$ to $\geq 17 \mathrm{~kg} / \mathrm{m}^{2}$ ) was detected in $6.3,10.6$, and $31.0 \%$ respondents, respectively. Age at first marriage $(A O R=2.76,95 \% \mathrm{Cl} 1.45,5.25)$, household food insecurity $(A O R=2.15,95 \% \mathrm{Cl} 1.05$, 4.41), inadequate dietary intake ( $A O R=2.93,95 \% \mathrm{Cl} 1.53,5.59)$, time to fetch water $(\mathrm{AOR}=2.31,95 \% \mathrm{Cl}$ $1.22,4.41)$, and meal frequency ( $A O R=2.0,95 \% \mathrm{Cl} 1.003$, 3.99) were found to be independent predictors of undernutrition.

Conclusions: The prevalence of undernutrition was relatively high among women of reproductive age in the Kunama community. Providing comprehensive and routine nutritional assessment, counseling women at all levels, and increasing involvement of organizations are recommended to address and prevent malnutrition.

\section{Background}

Malnutrition is one of the most devastating problems worldwide and is inextricably linked with poverty [1]. Malnutrition includes both undernutrition and overnutrition. Overnutrition refers to excessive intake of energy and/or macronutrients. Undernutrition can be divided

\footnotetext{
* Correspondence: sabasabina98@yahoo.com

${ }^{1}$ Dr. Tewelde Legesse Health Science College, Mekelle, Ethiopia

Full list of author information is available at the end of the article
}

into protein-energy malnutrition and micronutrient deficiencies [2]. Malnutrition among women is likely to have a major impact on their own health as well as their children's health. Maternal and child undernutrition is the underlying cause of at least 3.5 million deaths each year and $11 \%$ of the total global disease burden [1]. Recent evidence from developing countries indicates that malnourished women with a body mass index (BMI) below 
18.5 show a progressive increase in mortality rates as well as an increased risk of illness [2].

The 2011 Ethiopian Demographic and Health Survey (EDHS) also took weight and height measurements of women age 15-49. Twenty-seven percent of Ethiopian women are too thin. Women living in rural areas are more likely to be thinner than women living in urban areas (29 versus $20 \%$ ) [3]. In Tigray, the prevalence of underweight and overweight among women (15-49 age group) is 40 and $3.2 \%$, respectively, and undernutrition becomes one of the main major public health problems in Tigray [3].

Women in the reproductive age group and children are most vulnerable to malnutrition due to low dietary intakes, inequitable distribution of food within the household, improper food storage and preparation, dietary taboos, infectious diseases, and care. It is well known that chronic energy deficiency is a risk factor for adult low productivity, morbidity, and mortality, with chronic undernutrition among women additionally being a major risk factor for adverse birth outcomes for their children $[4,5]$.

The nutritional status of women before and during pregnancy is important for a healthy pregnancy outcome. The health extension program in Ethiopia has shown very encouraging results, and the government has now put in all sedentary rural areas a health extension program to reach every family in every Kebele for various preventive and health promotion services, including maternal and child nutrition and health facilities; nutrition service is designed and included in the national nutritional strategy to improve the health and nutritional status of women [6].

Ethiopia is struggling to achieve the Millennium Development Goals (MDGs), particularly goal five to decrease the maternal mortality rate as well as child mortality rate.

However, data on women's nutritional status and its associated factors is rather limited in particular areas such as the Kunama population which belongs to the minority group. Therefore, in this study, the magnitude of undernutrition and the associated factors among women of reproductive age belonging to the minority common was assessed.

\section{Methods}

\section{Study design, area, and population}

This community-based cross-sectional study was conducted on 284 women from Jan 27 to March 7, 2014 in Tahtay Adiyabo woreda Northwest Tigray specifically in two parts of Tahtay Adiyabo (Lemlem and Shimbelina). Pregnant and lactating mothers were excluded from the study for there would be temporary weight gain during these periods. The three largest ethnic groups reported in Tahtay Adiyabo are the Tigrayan, the Kunama, and foreign residents from Eritrea. There are 15 health posts and six health centers in the Tahtay Adiyabo woreda. There is one health post in Kunama catchment and one health center.

\section{Sample size calculation}

The sample size of the study was calculated using the formula for estimation of single population proportion by the assumption of: $P=$ proportion of women (15-49 age group) that are underweight were $40 \%$ in Tigray [3]. With an assumption of margin of error 0.05 at $95 \%$ confidence level and $10 \%$ non-response rate, using sample size reduction formula, the sample size was 284 . Finally, using simple random sampling technique, 284 households were selected. From each household, only one eligible woman at the reproductive age group was selected using simple manual lottery method, interviewed, and measured for her weight and height.

\section{Measurements}

The nutritional status of the women had been determined by taking weight in $\mathrm{kg}$ and height in $\mathrm{cm}$; weight had been measured using standardized digital Seka weight scale calibrated to $0.1 \mathrm{~kg}$, and height had been measured using Seka measuring rod calibrated to $0.5 \mathrm{~cm}$ [7]. All measurements had been taken twice and the average had been computed. When the two measurements differ by one unit, the measurement had been repeated.

Food diversity of women was determined using women dietary diversity score (WDDS). DDS had been assessed based on the number of food groups consumed over the immediate past $24 \mathrm{~h}$ [8]. Based on a set list of nine food items (starchy staples, dark-green leafy vegetables, oils and fats, other fruits and vegetables, organ meat, meats and fish, eggs, legumes, nuts and seeds, milk and milk products), a score lower than 4 was classified as low dietary diversity.

Food security had been assessed using a complete form of household food insecurity access scale (HFIAS), an 18-item scale developed by USAID, and the HFIAS indicators categorized the set of responses into two levels of household food security status: food secure and food insecure. Based on the responses given to the nine questions and frequency of occurrence over the past 30 days, households are assigned a score that ranges from 0 to 27 [9].

\section{Data collection and quality assurance}

Seven 10th grade-completed students who can fluently speak, read, write, and listen kunamigna and two diploma nurses as supervisor were recruited and trained for 2 days by the principal investigator on the study instrument, weight and height measurement, consent form, how to interview, and data collection procedure. The study subjects had been informed about the aim of the study and 
confidentiality issue, and informed consent had been secured from the study subject. The data were collected using face-to-face interview and anthropometric assessment. Tools used for the anthropometric assessment were calibrated daily before the assessment begins. After checking all questionnaires for consistency and completeness, the supervisor had presented the filled questionnaire to the principal investigator everyday. Additionally, in order to maintain the quality of the data, the principal investigator rechecked the completed questionnaires, and any problem faced at the time of data collection had been discussed and immediate solution had been given.

\section{Data analysis}

We analyzed data from 284 women. Descriptive analysis as proportions, percentages, frequency distribution, and measures of central tendency had been used. Both bivariate and multiple logistic regression analyses were used to examine associations of various factors with nutritional status of women of reproductive age. To control the effect of confounding factors, variables that had been found significant in bivariate analysis had entered into multivariate logistic regression in order to identify predictors of undernutrition among women of reproductive age with adjusted OR correspondence to $95 \%$ CI. Linearity, outliers, interaction, and multicollinearity had been checked for dichotomous data, and the $p$ value $<0.05$ cutoff point was considered as significant for all the independent variables in the model logistic regression employed. Statistical significance was set at $95 \% \mathrm{CI}$ and $p$ value $<0.05$. Analysis was conducted using SPSS Inc. version 20.

\section{Ethical considerations}

This study was approved by the Institutional Review Board of the Mekelle University College of Health Sciences. Then, an official letter was gained from the health bureau. Letter of permission was secured from administrative bodies of the area to communicate with relevant bodies in the community. Participation was voluntary, confidentiality ensured, and informed consent secured before the start of each interview.

\section{Results}

\section{Socio-demographic characteristics of respondents}

About 284 women of reproductive age were included with a response rate of $100 \%$. The mean age of the study participants was $28.5 \pm 8.97$ (SD) years of age. All participants were Orthodox Christians. More than half of the respondents 154 (54.2\%) were married. Majority of the participants $(218,76.8 \%)$ never attended formal school. The mean family size of the households was five. The mean monthly family income was 654 birr (US\$32.7). Only 154 $(54.2 \%)$ reported they had land (Table 1$)$.
Table 1 Socio demography characteristics of women of reproductive age in Kunama population, Northwest Tigray, February $2014(n=284)$

\begin{tabular}{|c|c|c|}
\hline Socio demographic characteristic & Frequency & Percentage \\
\hline \multicolumn{3}{|l|}{ Age of years } \\
\hline $15-19$ & 54 & 19.0 \\
\hline $20-29$ & 113 & 39.8 \\
\hline $30-39$ & 77 & 27.1 \\
\hline $40-49$ & 40 & 14.1 \\
\hline \multicolumn{3}{|l|}{ Marital status } \\
\hline Married (living with a partner) & 154 & 54.2 \\
\hline Living with no partner ${ }^{\mathrm{a}}$ & 130 & 45.8 \\
\hline \multicolumn{3}{|l|}{ Women educational status } \\
\hline No education & 218 & 76.8 \\
\hline Elementary & 49 & 17.2 \\
\hline High school & 17 & 6 \\
\hline \multicolumn{3}{|l|}{ Women occupation } \\
\hline Student & 35 & 12.3 \\
\hline Farmer & 191 & 67.3 \\
\hline Merchant & 48 & 16.9 \\
\hline Others & 10 & 3.5 \\
\hline \multicolumn{3}{|l|}{ Husband educational status $(n=154)$} \\
\hline No education & 105 & 68.2 \\
\hline Elementary & 32 & 20.8 \\
\hline High school & 17 & 11 \\
\hline \multicolumn{3}{|c|}{ Family monthly income (Ethiopian birr) } \\
\hline$<500$ & 81 & 28.5 \\
\hline $500-1000$ & 186 & 65.5 \\
\hline$>1000$ & 17 & 6 \\
\hline \multicolumn{3}{|l|}{ Family size } \\
\hline Less than 5 & 133 & 46.8 \\
\hline Greater than or equals to 5 & 151 & 53.2 \\
\hline \multicolumn{3}{|l|}{ Head of family } \\
\hline Father & 169 & 59.5 \\
\hline Mother & 115 & 40.5 \\
\hline \multicolumn{3}{|l|}{ Land ownership } \\
\hline Yes & 154 & 54.2 \\
\hline No & 130 & 45.8 \\
\hline \multicolumn{3}{|l|}{ Land in hectare $(n=154)$} \\
\hline Greater than or equal to 0.5 & 80 & 51.9 \\
\hline Less than 0.5 & 74 & 48.1 \\
\hline
\end{tabular}

Family size: the total number of individuals living in the same house a Living with no partner, including single $(n=48)$, widowed, and divorced

\section{Reproductive and obstetric history of respondents} Out of 236 respondents, 136 (57.6 \%) got married at the age of less than 18 , and the mean age of respondents at first marriage was $17 \pm 1.78$ (SD) years of age. The mean 
gravidness of respondents was $3.49 \pm 1.88$ (SD) and the mean parity was $3.24 \pm 1.69$ (SD). Among 223 respondents, 120 (53.8 \%) had given birth within the interval of 24-47 months (mean $31.17 \pm 1.69$ (SD)), and all of the respondents $(n=223)$ had breastfed their babies with a median of 24 months \pm 7.21 (SD) (Table 2).

\section{Respondent characteristics on diet and nutrition-related information}

All respondents stated that their commonest staple food was sorghum. No food taboos were reported by respondents. The food source of 231 (81.3\%) respondents was from their own product and market. More than half 148 $(52.1 \%)$ of the study participants had an experience of eating three meals per day regularly. Likewise, majority of the respondents (215. $75.7 \% ; 211,74.3 \%) ; 186$, $65.5 \%)$ used to consume fruit, vegetable, and meat per week, respectively. Of all respondents, 169 (59.5\%) had an exposure to nutritional information from different sources; majority $(127,75.2 \%)$ acquired the information from health professionals (Table 3 ).

\section{Nutritional status of women of reproductive age}

Among 284 respondents, more than half $(179,63 \%$ and $162,57.4 \%)$ were from food-secured households and had an inadequate dietary intake during the past $24 \mathrm{~h}$, respectively (Fig. 1). The mean household food security score was $11.47 \pm 5.24$ (SD) and the mean 24-h dietary recall score $4.3 \pm 1.05$ (SD).

Respondent characteristics of sanitation, health status, and other environmental factors

Among the respondents, 145 (51.1 \%) used open defecation. About 223 (78.5 \%) used water from a safe source (protected well and tap water) with a mean fetch time to collect water (per min) of $24.5 \pm 14.1$ (SD). Most of the respondents $(237,83.5 \%)$ never treat water. About $216(76.1 \%)$ had no illness within the last 2 weeks before the data collection (Table 4).

\section{Nutritional status (BMI) of women of reproductive age}

Of all respondents, 136 (47.9\%) (95\% CI 42.11$53.7 \%$ ) had a BMI less than $18.5 \mathrm{~kg} / \mathrm{m}^{2}$ while 148 (52.1\%) of the study participants had BMI $\geq 18.5 \mathrm{~kg} / \mathrm{m}^{2}$ (Fig. 2). The mean BMI of the respondents is $19.1 \pm$ 2.39 (SD). The mean height $(\mathrm{m})$ and weight $(\mathrm{kg})$ of respondents was $1.56 \pm 6.26(\mathrm{SD})$ and $46.7 \pm 6.33(\mathrm{SD})$, respectively.

\section{Factors associated with chronic energy deficiency among} Kunama women

The multivariate logistic regression analysis was done in looking for association of variables with nutritional status
Table 2 Reproductive and obstetric history of women in the reproductive age group in Kunama population, Northwest, Tigray, February 2014

\begin{tabular}{|c|c|c|}
\hline Reproductive and obstetric history & Frequency & Percentage \\
\hline \multicolumn{3}{|l|}{ Age of years at first marriage $(n=236)$} \\
\hline$<18$ & 136 & 57.6 \\
\hline$\geq 18$ & 100 & 42.4 \\
\hline \multicolumn{3}{|l|}{ History of contraceptive use ever } \\
\hline Yes & 158 & 55.6 \\
\hline No & 126 & 44.4 \\
\hline \multicolumn{3}{|l|}{ History of pregnancy } \\
\hline Yes & 223 & 78.5 \\
\hline No & 61 & 21.5 \\
\hline \multicolumn{3}{|l|}{ Gravidity $(n=223)$} \\
\hline $1-2$ & 83 & 37.2 \\
\hline $3-4$ & 68 & 30.5 \\
\hline$\geq 5$ & 72 & 32.3 \\
\hline \multicolumn{3}{|l|}{ History of ANC follow-up $(n=223)$} \\
\hline Yes & 125 & 56.1 \\
\hline No & 98 & 43.9 \\
\hline \multicolumn{3}{|l|}{$\begin{array}{l}\text { Nutritional information during ANC } \\
\text { follow-up }(n=223)\end{array}$} \\
\hline Yes & 99 & 44.4 \\
\hline No & 124 & 55.6 \\
\hline \multicolumn{3}{|l|}{$\begin{array}{l}\text { Iron supplementation during ANC } \\
\text { follow-up }(n=223)\end{array}$} \\
\hline Yes & 106 & 47.5 \\
\hline No & 117 & 52.5 \\
\hline \multicolumn{3}{|l|}{ Parity $(n=223)$} \\
\hline $1-2$ & 89 & 39.9 \\
\hline $3-4$ & 77 & 34.5 \\
\hline$\geq 5$ & 57 & 25.6 \\
\hline
\end{tabular}

Birth spacing between the last of 2 children $(n=223)$

$\begin{array}{lrl}\text { Not applicable (NA) } & 40 & 17.9 \\ <24 \text { months } & 32 & 14.3 \\ 24-47 \text { months } & 120 & 53.8 \\ \geq 48 \text { months } & 31 & 13.9 \\ \text { Breast feeding in months }(n=223) & & \\ \leq 24 \text { months } & 178 & 79.8 \\ >24 \text { months } & 45 & 20.2\end{array}$

ANC antenatal care, NA this refers to women who only had one birth during the study period

(BMI). Nutritional status was significantly associated with household food security, age at first marriage, time to fetch drinking water, women dietary diversity, and meal frequency (Table 5). 
Table 3 Respondent characteristic on diet and nutrition-related information of women in the reproductive age group in Kunama population, Northwest Tigray, February $2014(n=284)$

\begin{tabular}{|c|c|c|}
\hline Diet and nutrition-related information & Frequency & Percentage \\
\hline \multicolumn{3}{|l|}{ Source of food } \\
\hline Own product and market purchase & 231 & 81.3 \\
\hline Market purchase & 50 & 17.6 \\
\hline Own product & 3 & 1.1 \\
\hline \multicolumn{3}{|l|}{ Meal frequency per day } \\
\hline 3 times & 148 & 52.1 \\
\hline 2 times & 136 & 47.9 \\
\hline \multicolumn{3}{|l|}{ Access to any nutritional information } \\
\hline Yes & 169 & 59.5 \\
\hline No & 115 & 40.5 \\
\hline \multicolumn{3}{|l|}{ Source of information $(n=169)$} \\
\hline Health professional & 127 & 75.2 \\
\hline Media & 10 & 5.9 \\
\hline School & 22 & 13 \\
\hline Peers & 10 & 5.9 \\
\hline \multicolumn{3}{|l|}{ Frequency of fruit intake } \\
\hline Never & 32 & 11.3 \\
\hline Weekly & 215 & 75.7 \\
\hline Monthly & 37 & 13 \\
\hline \multicolumn{3}{|l|}{ Frequency of vegetable intake } \\
\hline Daily & 51 & 18 \\
\hline Weekly & 211 & 74.3 \\
\hline Never and monthly & 22 & 7.7 \\
\hline \multicolumn{3}{|l|}{ Frequency of animal source intake } \\
\hline Weekly & 186 & 65.5 \\
\hline Never and monthly & 98 & 34.5 \\
\hline
\end{tabular}

\section{Discussion}

According to this study, the prevalence of overall undernutrition was $47.9 \%$ (95\% CI 42.11-53.7\%). This was found higher (47.9\%) than findings from the sub-Saharan Demographic and Health Survey (DHS), which ranges from 7 to $37 \%$ [10]. Looking particularly to Ethiopians, the national average was $27 \%$ as well as the regional (Tigray) average of $40 \%$ [3]. The dissimilarity could be due to countries' DHS reports which used to include participants from both the rural and urban. Studies including EDHS 2011 and meta analysis conducted in many countries included 26 sub-Saharan countries; results showed that the prevalence of undernutrition was higher among rural women than urban $[3,11]$.

The reason for the higher prevalence seen in this study could be that the national as well as the regional EDHS reports included all women of reproductive age from rural and urban areas [3]. This could underestimate the prevalence of undernutrition. The prevalence of undernutrition in this study is also higher than the prevalence seen among Arsi's women (47.9 versus $26.7 \%)$. This could be due to the regional variation of undernutrition. According to a study done based on the EDHS report, women living in Tigray were two times more likely to be malnourished than women in the Oromiya Region [12]. Tigray is mountainous and thus makes farming difficult, which puts women in Tigray at a higher risk of malnutrition than in other regions of Ethiopia.

Earlier studies also showed that the prevalence of undernutrition in Kerala (India), Bangladesh (Asia), Purworejo, and in slum Dhaka was 19, 34, 17, and $30.8 \%$, respectively [13-16], which is lower than the prevalence of undernutrition in this study (47.9\%). This could be due to the higher food insecurity (37\%) leading to lack of access to adequate, safe, and nutritious food resulting to undernutrition. There was also a large number of subjects (57 \%) taking inadequate

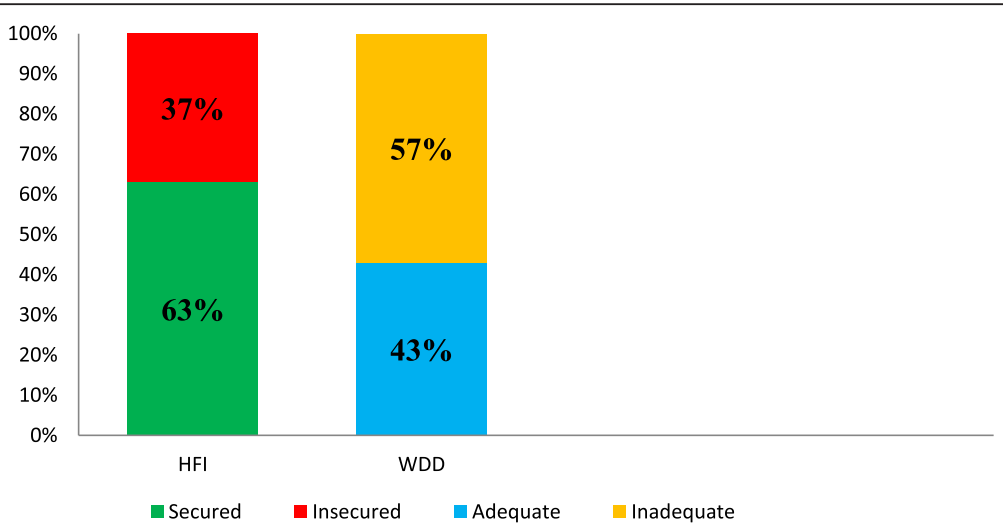

Fig. 1 Nutritional status of women in reproductive age group in Kunama population, Northwest Tigray, Ethiopia, February 2014. NB: HFI household food insecurity, WDD women dietary diversity 
Table 4 Respondent characteristics of sanitation, health status, and other environmental factors among women of reproductive age in Kunama population, NorthwestTigray, Ethiopia, February 2014

\begin{tabular}{|c|c|c|}
\hline Variables & Frequency & Percentage \\
\hline \multicolumn{3}{|l|}{ Latrine availability } \\
\hline Yes & 139 & 48.9 \\
\hline No & 145 & 51.1 \\
\hline \multicolumn{3}{|l|}{ Type of latrine $(n=139)$} \\
\hline Unimproved pit latrine & 139 & 100 \\
\hline \multicolumn{3}{|l|}{ Source of water } \\
\hline Protected & 223 & 78.5 \\
\hline Unprotected & 61 & 21.5 \\
\hline \multicolumn{3}{|l|}{ Time to fetch drinking water } \\
\hline$<30$ min & 171 & 60.2 \\
\hline$\geq 30 \min$ & 113 & 39.8 \\
\hline \multicolumn{3}{|l|}{ Water treatment practice } \\
\hline Yes & 47 & 16.5 \\
\hline No & 237 & 83.5 \\
\hline \multicolumn{3}{|c|}{ Water treatment mechanism $(n=47)$} \\
\hline Sieve through cloth & 30 & 63.8 \\
\hline Filter & 4 & 8.5 \\
\hline Wuha agar & 13 & 27.7 \\
\hline \multicolumn{3}{|l|}{ Hand washing } \\
\hline Only before eating & 81 & 28.5 \\
\hline Before eating and after toilet & 203 & 71.5 \\
\hline \multicolumn{3}{|l|}{ Washing agents } \\
\hline Soap & 138 & 48.6 \\
\hline None & 146 & 51.4 \\
\hline \multicolumn{3}{|c|}{ Attack of illness for the last 2 weeks } \\
\hline Yes & 68 & 23.9 \\
\hline No & 216 & 76.1 \\
\hline \multicolumn{3}{|l|}{ Type of disease $(n=68)$} \\
\hline Malaria & 38 & 55.9 \\
\hline Intestinal parasite & 12 & 17.6 \\
\hline Kal azar & 7 & 10.3 \\
\hline Unspecified disease & 11 & 16.2 \\
\hline \multicolumn{3}{|l|}{ Health service access ( $n=68$ ) } \\
\hline Yes & 65 & 95.6 \\
\hline No & 3 & 4.4 \\
\hline \multicolumn{3}{|l|}{ Place of health service $(n=65)$} \\
\hline Governmental & 52 & 80 \\
\hline Private & 13 & 20 \\
\hline
\end{tabular}

NB: protected source of water-protected well and tap water. Unprotected source of water-unprotected well and river

dietary diversified food which reflects low micronutrient intake, affecting and compromising their immunity and indirectly resulting in undernutrition.
Women who were taking inadequate diversified food were 2.93 times more likely to be undernourished as compared to those who were taking adequate diversified food. The same result was found in studies done in rural Kenya and Burkina Faso among women of reproductive age [17]. Nevertheless, the result of this study is inconsistent with the result done in six states of Nigeria regarding the dietary diversity score. In this study, lower diet diversity score (4.3 vs 5.81 ) and higher magnitude of undernutrition ( 47.9 vs $11.3 \%$ ) was seen. This could be the reason for the inconsistency of the mentioned results regarding respondents' dietary diversity score [18].

Household food security was positively associated with nutritional status. Women from food-insecure households were 2 times more likely to be undernourished than those women who were from food-secure households. But results from studies done in rural Malaysia and Bangladesh showed no association between food security and nutritional status. This contradiction seen could be due to the difference in assessment tool used. Unlike studies from Malaysia and Bangladesh which used a single question, we used standard multiple questions to assess food insecurity $[19,20]$. Household food security is one of the indicators of nutritional status of women. Household food insecurity arises when families do not have enough to eat due to food being neither available nor accessible.

In this study, women having twice per day meal frequency were two times more likely to be undernourished. The result was consistent with an earlier study conducted in the Arsi zone, Oromiya. However, meal frequency had not shown any association with undernutrition in a study done among Bangladesh women of reproductive age. The contradiction could be due to the fact that $78.2 \%$ of the study participants from rural Bangladesh could not afford two meals per day. So, it is tricky to see the effect of meal frequency on respondents which had adequate meal frequency and inadequate meal frequency per day while all of them could not afford two meals or more per day [19].

Those women who were married at the age of 18 and less were more likely to be undernourished than those who were married at the age of 18 and above. The result was the same with that of a study done in Nigeria [21]. Women married at an early age were exposed to frequent child bearing, unplanned motherhood, and abortion, which affected their nutritional status [22].

Those who spent greater than $30 \mathrm{~min}$ to fetch water were 2.3 times more likely to be undernourished than those who only spent less than $30 \mathrm{~min}$. Engaging in such activities is mainly a responsibility of women. This might increase the energy consumption of the body, and in the mean time, they would get tired, but still they would have the responsibility to prepare food for the rest of the family members afterwards. This may undermine women's wellbeing, including nutrition, in substantive ways. 


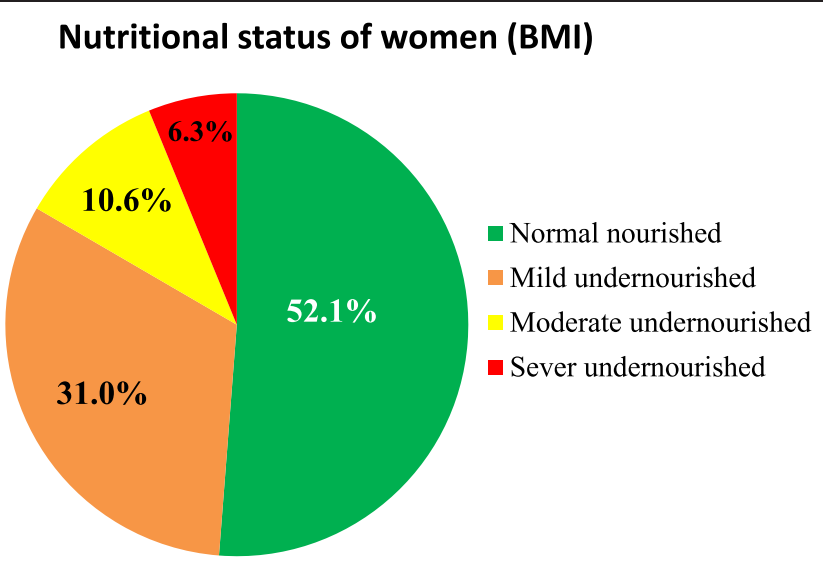

Severe under nutrition (BMI $<16 \mathrm{~kg} / \mathrm{m} 2$ ), moderate under nutrition (BMI $<17$ to $\geq 16 \mathrm{~kg} / \mathrm{m} 2$ ), and mild under nutrition (BMI $<18.5$ to $\geq 17 \mathrm{~kg} / \mathrm{m} 2$ )

Fig. 2 Nutritional status (BMI) of women of reproductive age in Kunama population, Northwest Tigray, Ethiopia, February 2014

Table 5 Logistic regression of nutritional status (BMI) and predictors among women of reproductive age in Kunama population, Northwest Tigray, Ethiopia, February 2014

\begin{tabular}{|c|c|c|c|c|c|}
\hline \multirow[t]{2}{*}{ Predictors } & \multirow[t]{2}{*}{ Category } & \multicolumn{2}{|l|}{ Nutritional status } & \multicolumn{2}{|l|}{ Odds ratio $(95 \% \mathrm{Cl})$} \\
\hline & & Undernutrition & Normal & COR & AOR \\
\hline \multirow[t]{2}{*}{ Marital status } & Married & 65 & 89 & 1 & 1 \\
\hline & Living with no partner & 71 & 59 & $1.648(1.029-2.638)^{*}$ & $1.234(0.584-2.604)$ \\
\hline \multirow[t]{2}{*}{ Ever used contraceptive } & Yes & 58 & 100 & 1 & 1 \\
\hline & No & 78 & 48 & $2.802(1.727-4.544)^{*}$ & $1.923(0.975-3.792)$ \\
\hline \multirow[t]{2}{*}{ Meal frequency } & Twice per day & 84 & 52 & $2.982(1.839-4.835)^{*}$ & $2.002(1.003-3.993)^{* *}$ \\
\hline & 3 times per day & 52 & 96 & 1 & 1 \\
\hline \multirow[t]{2}{*}{ Intake of animal source foods } & Weekly & 73 & 113 & 1 & 1 \\
\hline & Never and monthly & 63 & 35 & $2.786(1.678-4.627)^{*}$ & $1.581(0.791-3.150)$ \\
\hline \multirow[t]{2}{*}{ WDD } & Adequate & 41 & 81 & 1 & 1 \\
\hline & Inadequate & 95 & 67 & $2.901(1.776-4.740)^{*}$ & $2.931(1.536-5.592)^{* *}$ \\
\hline \multirow[t]{2}{*}{$\mathrm{HFI}$} & Secured & 70 & 109 & 1 & 1 \\
\hline & Insecure & 66 & 39 & $2.635(1.603-4.331)^{*}$ & $2.158(1.051-4.417)^{* *}$ \\
\hline \multirow[t]{2}{*}{ Hand washing agent } & Soap & 56 & 82 & 1 & 1 \\
\hline & None & 80 & 66 & $1.775(1.108-2.842)^{*}$ & $1.313(0.683-2.524)$ \\
\hline \multirow[t]{2}{*}{ Family size } & $<5$ & 54 & 79 & 1 & 1 \\
\hline & $\geq 5$ & 82 & 69 & $1.739(1.085-2.786)^{*}$ & $1.293(0.485-3.446)$ \\
\hline \multirow[t]{2}{*}{ Age at first marriage } & $<18$ & 85 & 51 & $3.889(2.242-6.746)^{*}$ & $2.761(1.450-5.255)^{* *}$ \\
\hline & $\geq 18$ & 30 & 70 & 1 & 1 \\
\hline \multirow[t]{3}{*}{ Gravidity } & Gravid 1-2 & 32 & 51 & 1 & 1 \\
\hline & Gravid 3-4 & 33 & 35 & $1.503(0.785-2.876)$ & $1.917(0.851-4.320)$ \\
\hline & Gravid $\geq 5$ & 40 & 32 & $1.992(1.049-3.784)^{*}$ & $1.31(0.567-3.026)$ \\
\hline \multirow[t]{2}{*}{ Time to fetch drinking water } & $<30 \min$ & 66 & 105 & 1 & 1 \\
\hline & $\geq 30 \min$ & 70 & 43 & $2.590(1.588-4.223)^{*}$ & $2.322(1.220-4.416)^{* *}$ \\
\hline
\end{tabular}

COR crude odds ration, $A O R$ adjusted odds ration, $\mathrm{HFI}$ household food insecurity, WDD women dietary diversity score

Reminder: ${ }^{* *}$ significant in both bivariate and multi variant; ${ }^{*} p<0.05$ (2-tailed); stepwise (backward LR) was used in logistic regression. $1=$ reference 
No association was found between educational level and undernutrition in this study (AOR $0.9 \%$ CI 0.49-17). However, the educational level of women of reproductive age had a positive association with the nutritional status of women in studies conducted in India, Bangladesh, and Arsi Oromiya. The prevalence of chronic energy deficiency (CED) was $33.9 \%$, and the prevalence of CED was almost four times higher among women with no education than those with 12 and more years of schooling in India [23-25]. The reason might be due to the fact that food and related factors that have an effect on nutritional status of women are under the control of the household head. About $74.8 \%$ of women who headed their household were with no education. It was reported that most respondents (80 \%) at the age of 15-19 went to school and are currently living with their parents so that they have not any power to decide on nutrition and related issues of the household even though they had better education than their parents.

\section{Conclusions}

Undernutrition is a very dreading condition, and it is evident the condition is higher among rural women of reproductive age. The current study showed high prevalence of undernutrition/chronic energy deficiency (BMI $<18.5$ $\mathrm{kg} / \mathrm{m}^{2}$ ) among women of reproductive age in the study area. The majority of women were with inadequate dietary diversity score. Undernutrition (BMI $<18.5 \mathrm{~kg} / \mathrm{m}^{2}$ ) in women of reproductive age were found to have associated with factors such as age at first marriage, meal frequency, household food insecurity, dietary intake, and time to fetch drinking water collection. Interventions like nutritional rehabilitation, health education regarding micronutrient intake, and early marriage carryout continuous nutritional assessment and screening needs to be applied.

Drafted policies need to be enhanced by targeting towards the food security, particularly in food-insecure households as to increase their agricultural productivity, strengthen their income, and empower women.

Governmental and nongovernmental organizations need to contribute on building of water taps to offer protected waters and for the source to be in reach.

The staple food of all the study participants was sorghum and the consumption of teff; organ meat that are rich in iron was low. It will be vital to conduct studies on the prevalence of anemia and its associated factors among women of the reproductive age.

\section{Competing interests}

The authors declare that they have no competing interests.

\section{Authors' contributions}

SA participated in the conception and design of the study and coordinated the data collection. SA, AS, and GM analyzed the data; SA drafted the manuscript. SA, AS, and GM were involved in the conception, design of the study, fieldwork, and review of the manuscript. All authors read and approved the final manuscript.

\section{Acknowledgements}

We acknowledge the study participants and the administrative for the information provided. Save the Children, Ethiopia, funded the study.

\section{Author details}

${ }^{1}$ Dr. Tewelde Legesse Health Science College, Mekelle, Ethiopia. ${ }^{2}$ Public Health Department, College of Health Sciences, Mekelle University, Mekelle, Ethiopia.

Received: 2 February 2015 Accepted: 28 May 2015

Published online: 22 June 2015

\section{References}

1. Mesfin Tafa and Jemal Haider; Effect of modern family planning methods use on nutritional status of women of reproductive age group at Tena district, Arsi Zone, Ethiopia, international conference on family planning , A.A, Ethiopia,2013

2. Manju Dewan. Malnutrition among Indian women, Stud. Home Comm. Sci., 2(1): 7-10 (2008)

3. Ethiopia Central Statistical Agency and ICF International. 2011 Ethiopia Demographic and Health Survey: key findings. Calverton, Maryland, USA: CSA and ICF International; 2012.

4. Girma W, Genebo T. Determinants of nutritional status of women and children in Ethiopia. Calverton, Maryland, USA: ORC Macro; 2002.

5. Subramanian SV, Smith G. Patterns, distribution and determinants of under and over nutrition; a population based study of women in India. Am J Clin Nutr. 2006;84:633-40.

6. Save the children; Ethiopian national nutrition strategy review and analysis of progress and goals; one year on, May 2009 (http://www.disasterriskreduction.net)

7. CDC: National health and nutrition examination survey: anthropometry procedures manual: 2007. (May 20-2012): available from http:// www.cdc.gov/nchs/data/ad/ad361.

8. FAO-FANTA: Guidelines for measuring household and individual dietary diversity. FAO Nutrition and Consumer Protection Division, Rome, Italy; 2011:1-56.

9. USAID: Household food insecurity access scale (HFIAS) for measurement of food access: indicator guide VERSION 3. Washington, D.C: Academy for Educational Development; 2007.

10. Macro International Inc. Nutrition of young children and women, Ethiopia Calverton, Maryland, USA: Macro International Inc.), 2008

11. Uthman OA, Alemu $O$, malnutrition among women in sub Saharan Africa; rural-urban disparity rural and remote health 8;931, 2008 (http; WWW.rrh.org.au)

12. Bitew, Fikrewold H. and Daniel S. Telake. 2010. Undernutrition among women in Ethiopia: rural-urban disparity. DHS Working Papers No. 77. Calverton, Maryland, USA: ICF Macro.

13. Mostafa Kamal and Md Aynul Islam; Socioeconomic correlates of malnutrition among married women in Bangladesh, mal J Nutr 16 (3): 349-359,2010.

14. P. Ramesh; Malnutrition among women in Kerala: an analysis of trends, differentials and determinants, Gokhale Institute of Politics and Economics (Deemed University) Pune - 411004 Maharashtra, India, 2011.

15. Jaqueline Knowles, Vanuatu Nutrition Survey 2007, UNICEF Pacific Office, Fiji

16. Haque MJ, nutritional status of the women of reproductive age with some of their socio demographic characteristics of a slum in Dhaka, Dinajpur MED col J 2009, Jan (2 (1):2-7)

17. M. Savy, Dietary diversity score and nutritional status of women change during the seasonal food shortage in rural Burkina Faso, J. nutria 136: 2625-2632, 2006).

18. Sanusi $R$, An assessment of dietary diversity in six Nigerian states, Afr. J. Biomed. Res.13 (Sep 2010): 161-167

19. Farhana Haseen. Malnutrition among Bangladeshi women in ultra poor households; prevalence and determinants, international maternal and child health, department of women's and children's health 2005, Uppsala university

20. A.N Ihab. Nutritional outcomes related to household food insecurity among mothers in rural Malaysia, J health popul Nutr. 2013;31(4):480-489.

21. Ene-Obong HN et al.; Determinants of health and nutritional status of rural Nigerian women J Health Popul Nutr. 2001;19(4):320-330.

22. UNICEF, the state of the world's children 2011. (WWW.Childinfo.Org). 
23. Faber and Wenhold; Nutrition in contemporary South Africa, water SA Vol. 33 No.3, 2007. (www.wrc.org.za).

24. Kulasekaran RA. The influence of mothers' chronic energy deficiency on the nutritional status of preschool children in Empowered Action Group states in India. Int J Nutr Pharmacol Neurol Dis. 2012;2:198-209.

25. Abul hasnat; prevalence and determinants of malnutrition among reproductive aged women of rural Bangladesh, Asia Pac J public health 2010, http://aph.sagepub.com/content/22/1/110.refs.html.

Submit your next manuscript to BioMed Central and take full advantage of:

- Convenient online submission

- Thorough peer review

- No space constraints or color figure charges

- Immediate publication on acceptance

- Inclusion in PubMed, CAS, Scopus and Google Scholar

- Research which is freely available for redistribution 